\title{
Are withholding and withdrawing therapy always morally equivalent?
}

\author{
Daniel P Sulmasy and Jeremy Sugarman Georgetown University Medical Center and Duke University \\ Medical Center, USA, respectively
}

\begin{abstract}
Many medical ethicists accept the thesis that there is no moral difference between withholding and withdrawing life-sustaining therapy. In this paper, we offer an interesting counterexample which shows that this thesis is not always true. Withholding is distinguished from withdrawing by the simple fact that therapy must have already been initiated in order to speak coherently about withdrawal. Provided that there is a genuine need and that therapy is biomedically effective, the historical fact that therapy has been initiated entails a claim to continue therapy that cannot be attributed to patients who have not yet received therapy. This intrinsic difference between withholding and withdrawing therapy is of moral importance. In many instances, patients will waive this claim. But when one considers withdrawing therapy from one patient to help another in a setting of scarce resources, this intrinsic moral difference comes into sharp focus. In an era of shrinking medical resources, this difference cannot be ignored.
\end{abstract}

Several ethicists have argued that despite differences in the emotional reaction of caregivers, there is really no moral difference between withholding and withdrawing life-sustaining therapy $(1,2,3)$. In agreement with these authors, we separate the question of withholding and withdrawing from related questions regarding potential distinctions such as active/passive, act/omission, and killing/ allowing to die (4). Stated precisely, the Equivalence Thesis we wish to examine asserts that:

1) If it would have been morally permissible to have withheld a therapy (that has in fact already been started), then it is now morally permissible to withdraw that therapy.

and

2) If, in the future, it would be morally permissible to withdraw a therapy (that has in fact not yet been

\section{Key words}

Ethics; medical ethics; withholding treatment; allowing to die; justice; resource allocation. started), then it is now morally permissible to withhold that therapy.

This thesis cannot simply be expressed as a logical is equivalence between the morality of withholding $\vec{\infty}$ and the morality of withdrawing therapy. Such 음 equivalence would imply an atemporal, anhistorical $\underset{ }{-}$ perspective that cannot obtain in reality. One cannot, at any single point in time, actually face a $\varnothing_{\varnothing}^{\mathbb{D}}$ choice of either now withholding or now 3 withdrawing therapy from any single individual. Something temporal, by definition, distinguishes withholding from withdrawing: the historical fact of the initiation of therapy. Therefore the thesis is beg $f$ expressed in contrary to fact conditionals, supposing that things were to be (or were to have been) other than they actually are.

Opposition to the Equivalence Thesis has been especially strong from religious groups. In particular, $\stackrel{D}{\perp}$ Jewish medical ethicists teach that there is a morally $\overrightarrow{\vec{P}}$ relevant distinction between withholding and 3 withdrawing life-sustaining medical treatment (5). Philosophically trained medical ethicists who hold that there is no moral difference between withholding and withdrawing have suggested a workable approach to those who believe otherwise. They suggest that since the principle of autonomy favours respect for idiosyncratic patient beliefs, physicians and other caregivers ought to respect the religious beliefs of patients who hold the view that there 을 is a moral distinction between withholding and $\supset$ withdrawing therapy even though such views cannot be sustained philosophically.

To our knowledge, no convincing philosophical arguments, devoid of religious content, have 0 suggested that the distinction between withholding $\omega$ and withdrawing therapy has any moral significance. We present a case that we believe demonstrates, on aco philosophical basis, that the Equivalence Thesis is not true in all circumstances.

\section{Case}

Imagine that you are a physician practising in $\stackrel{\mathbb{Q}}{\Omega}$ Dilemmaland. Identical twin infants, Prima and Secunda, both born by Caesarean section, have been 
subjected to carbon monoxide (CO) poisoning at the same time, from the same source, for the same duration of exposure, and are now cyanotic and in distress. The paramedics are called, and Prima and Secunda are intubated. Hyperbaric oxygen is not available. Respirators are in scarce supply, and only one respirator with one oxygen tank and tubing is available in all of Dilemmaland. When the ambulance arrives at the emergency room, the physicians inform the paramedics that there is unfortunately only one respirator available. The team decides to 'make the best of a bad situation'. They make a random choice between the twins by a fair toss of a fair coin. Prima wins the toss, and is hooked up to the respirator. The twins are absolutely equal in every conceivable biological way, including their respective prognoses for recovery from $\mathrm{CO}$ poisoning. Without further action, this equality will, of course, change dramatically in a few minutes, but not in the time it would take to switch the respirator from one to the other. In this case then, withholding or withdrawing therapy from one twin is biomedically equivalent to withholding or withdrawing therapy from the other. Further, it is not possible to cycle the respirator from one twin to the next. If this is attempted, both will die. Treatment of CO poisoning requires sustained high concentrations of oxygen and continuous assisted ventilation.

Imagine that the twins' parents come quickly upon the scene, announce that since Prima cries more, Secunda is their favourite. They request that the physicians immediately disconnect Prima and hook up Secunda. How ought the physicians to reply?

\section{Discussion}

Almost everyone would accept the morality of the initial decision to withhold therapy from Secunda to save Prima. But many might find it surprising to note that, according to the Equivalence Thesis, compliance with the parents' request to withdraw therapy from one twin for the sake of the other is not morally different from the initial decision to withhold therapy from one twin for the sake of the other. Proposition one of the Equivalence Thesis states that if it would have been morally permissible to have withheld therapy, then it is now permissible to withdraw therapy. Certainly if it were the case that Prima had not been connected, it would have been permissible to have withheld the respirator from Prima and to have connected Secunda instead. Therefore, according to the Equivalence Thesis, it must now be permissible to withdraw the respirator from Prima. The medical conditions of the twins, as described, are equivalent. There would be no net difference in outcome.

But we suspect that many persons would object to this course of action. It does not seem that detaching Prima in order to save Secunda is morally equivalent to never having attached Prima and instead attaching Secunda to the respirator in the first instance. And if these two actions are morally different, the Equivalence Thesis is false.

\section{WITHHOLDING, WITHDRAWING AND ORIGINAL}

ACQUISITION

We argue that withholding and withdrawing are not always morally equivalent, and this case illustrates why. Prima and Secunda are biologically equivalent in all ways that seem relevant and have equal moral claims on the respirator. In the first instance, given the moral dilemma described, tossing a coin seems to be a fair way to decide, since a fair toss of a fair coin gives each twin an equal chance at survival. Once one twin has been connected, however, the historical fact of that connection itself constitutes a moral claim to continue to be connected to the respirator. While we reject the broad application of Nozick's Principle of Original Acquisition of Holdings, in the circumstances of this particular case Nozick's principle seems to explain Prima's claim on the respirator (6). This principle is never relevant to withholding. Yet there is a claim to original acquisition that arises whenever one has already been started on a therapy, and this claim must be considered whenever one contemplates withdrawing therapy. This is a claim that is only valid if it is based in clinical reality. It can neither be invoked in the absence of medical need nor in cases of biomedically ineffective therapy. Nor is this a claim to an inalienable right. It is a claim that can be waived, and dying patients will often waive it. Prima's claim (a claim that she herself cannot waive), is based on clinical reality and on her original acquisition. Indeed, it would seem to have a stronger moral basis than the arbitrary favouritism displayed by the parents. The coin toss that resulted in Prima's original acquisition of the respirator was fair. Therapy that could have been withheld morally from Prima if she had lost, cannot now be withdrawn morally. Thus, withholding and withdrawing are not morally equivalent in this case. Further, under the conditions of this case, the effects of this 'social lottery' cannot be remedied in a manner that would benefit the least well off twin and satisfy the conditions of Rawls's difference principle (7). The claim to continued treatment, accruing from the original acquisition that accompanies the state of being treated, a state that is in turn necessary to enable one to speak coherently of withdrawing therapy, is intrinsic to the difference between withholding and withdrawing. This is a moral difference, not a mere psychological difference. (Prima has no psychological expectations.) This claim may be waived by patients or their surrogates, but it ought never to be ignored.

IS THE METHOD OF CHOOSING WHAT REALLY MATTERS?

Some might object that what matters morally in this case is the difference in the methods of choosing 
between the twins, and not the fact that one has already been chosen and is already undergoing therapy that would be withdrawn. But this does not seem correct. Even if the parents had asked for a repeat coin toss (in which case the method of choosing in the first instance would be exactly the same as the proposed second method), the claims accruing from Prima's original acquisition would seem to be violated by subjecting her to a 50 per cent chance of losing what she had already gained. Further, even if the initial method of choosing between the twins had been unfair (for example, choosing Prima because she looked cute), Prima could not be held morally responsible for the unfair decision from which she benefited, and she would still have a reasonable claim to the respirator by virtue of the fact that she had already been started on therapy and held original acquisition. This implies that, at least in the circumstances of this case, withholding and withdrawing therapy are not morally equivalent.

\section{IS THE REVERSAL OF A JUST CHOICE THE ISSUE?}

Some might object that the real moral issue is not that there is a difference between withholding and withdrawing, but that a just choice would be reversed. But surely those who would raise this argument would not suggest that once a fair decision has been made it cannot be reversed. If that were so, then no one who justly starts on a therapy could ever be withdrawn from that therapy. We would argue strongly against such a position. In fact, on closer scrutiny, this objection seems to be really only another way of stating that there is a difference between withholding and withdrawing. If a decision to start a therapy has been justly made, then the patient has a strong claim to continue that therapy unless he or she waives this claim. Further, as we argued above, even if the original choice were unjust, an innocent party benefiting from that unjust decision may still have a valid claim to continue treatment.

\section{ARE PRIMA AND SECUNDA MORALLY EQUIVALENT?}

Some might insist that the Equivalence Thesis is true, and suggest that it is the premise that Prima and Secunda are morally equivalent that is false. After all, Prima is not Secunda, and this difference is demonstrated by the fact that Prima is now attached to the respirator, while Secunda is not now attached to the respirator. But this argument seems only to beg the question, because what is at issue is precisely the question of whether or not being attached to the respirator now makes a moral difference. Being on the respirator now is what constitutes the difference between withholding and withdrawing. To suggest that the only relevant moral difference between Prima and Secunda is that one twin is attached to the respirator while the other is not is precisely our point. Further, we have carefully constructed the case so that this is the only difference between the $\frac{\varnothing}{\varrho}$ twins. To try to argue against the distinction by $\overrightarrow{\overrightarrow{\vec{\sigma}}}$. modifying the case so that the twins are dissimilar in other ways is to concede that the difference we $\vec{F}$ describe is morally important.

IS THE QUESTION REALLY ABOUT PARENTS' RIGHTS? Others might suggest that the fact that Secunda is $\frac{\bar{s}}{\sigma}$ valued more by her parents is a relevant moral $\unrhd$

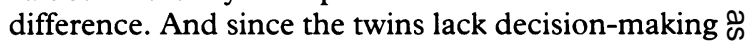
capacity, the parents seem to be the morally valid $\vec{\circ}$ surrogates. But in the face of the favouritism shown by the parents, how could one suggest that the $\vec{\omega}$ parents were either advocating the best interests of Prima or somehow anticipating her own autonomous judgements? Their conflict of interest, $\sim$ apparently favouring one twin over the other, might disqualify them as valid surrogates. In this case, the $i$ best argument the parents could make is that they $\vec{\infty}$ have the right to make decisions like the one faced by the protagonist in Sophie's Choice (8). In Styron's tragic tale, Sophie is forced to choose which of her $\nabla_{\mathbb{D}}$ two children will be killed by Nazi soldiers in order $\varnothing_{\varnothing}$ for her and the remaining child to survive. This $\rightrightarrows$ forced choice causes Sophie great emotional turmoil and regret. In our case, the parents of Prima and Secunda would be requesting responsibility for $3 \notin$ tragic decision that has, in fact, already been ma for them. Any claim they might make to a right such responsibility seems more narcissistic the heroic, and weaker than Prima's claim on the respirator.

IS THIS REALLY JUST A CASE ABOUT SCARCE RESOURCES?

Still others might argue that this is really a classic justice problem about allocating scarce resources? and not a case about withholding and withdrawing therapy. While this is a potentially significant objection, we argue that it introduces a false $\frac{0}{3}$ dichotomy. The particularities of this case make it impossible to separate the claims of justice from the 0 distinction between withholding and withdrawing. The difference between withholding and with-옥 drawing, which is inseparable from the difference $>$ between being treated now and never having been treated, simply constitutes the justice issue in this case.

Every case in ethics must arise in a particular context. Withholding and withdrawing are only different because something has happened in an unfolding case history: a therapy has been started. 0 Withholding and withdrawing cannot be considered outside of some context. For example, some ethicists $\stackrel{?}{?}$ argue that withdrawing is often morally preferable to $\frac{7}{0}$ withholding in cases where one needs time to $\frac{\vec{C}}{\mathbb{D}}$ determine whether or not the therapy is effective $\stackrel{?}{?}$ $(9,10)$. In fact, this contradicts proposition two of $\stackrel{\mathbb{Q}}{\varrho}$ the Equivalence Thesis. In such contexts, it is not true that if it would be, in the future, permissible to 
withdraw therapy, it is now permissible to withhold therapy. It might be the case that it only becomes permissible to withdraw therapy once one has tried it and concluded that it will fail. The context makes a difference.

JUSTICE AND THE CASH VALUE OF THE DISTINCTION Our argument in this paper is that there is always an intrinsic moral difference between withholding and withdrawing therapy. This difference may be more or less apparent, depending upon the context. The difference lies in the patient's prima facie claim to continue therapy once it has been started. If the patient waives this claim, or if surrogates can construe that the patient would have waived the claim, this difference becomes moot. Since the paradigm cases for discussing withholding and withdrawing are cases where the patient waives the claim to continued therapy and the doctor wants to persist, it has seemed to many that there is no moral difference. But if doctors consider removing a therapy when the patient's claim has not been waived, even if it would have been moral to have withheld that therapy without the patient's consent in the first place, the difference comes into sharp focus.

This sort of circumstance arises in genuine triage settings. Suppose that there is only one ventilator left in an intensive care unit. Suppose that two patients arrive, one with a 50 per cent chance of surviving on a ventilator, and one with a 90 per cent chance of surviving on a ventilator. Without the ventilator, both will die. Other things being equal, most physicians would put the patient with the better chance for survival on the ventilator. In such a situation, even the patients would probably think the decision tragic, but fair.

But if the patient with the 50 per cent chance of survival were already on the only ventilator, and the patient with the better prognosis arrived, also requiring ventilator support, the situation would be different. This is so even though it would have been fair to have withheld the ventilator from the patient with the 50 per cent prognosis for the sake of the patient with the 90 per cent prognosis. Despite the difference in the probability of a good outcome, the patient who is already on the ventilator has at least some claim to continue treatment. And if that is so, withholding and withdrawing are not morally equivalent in such a situation.

\section{Conclusion}

If a patient has a genuine medical need for a therapy that is not biomedically futile, and that therapy has been initiated, the patient has a legitimate claim to continue that therapy unless he or she waives this claim. Because this is so, in some circumstances more justification may be required in order to withdraw a therapy than would have been required in order to have withheld it. This refutes proposition one of the Equivalence Thesis. As pointed out above, it is also widely conceded that in certain instances more justification may be required in order to withhold a therapy than would be required in order to withdraw it at a later time. This refutes proposition two of the Equivalence Thesis. We therefore conclude that the Equivalence Thesis is not a universal law of bioethics.

In an era marked by increasing concern regarding the scarcity of medical resources, many feel that our health care facilities are becoming, on both a micro and a macro level, increasingly like Dilemmaland. Our discussion sounds a particularly important cautionary note. Withholding and withdrawing lifesustaining therapy are not morally equivalent acts unless the patient who has been started on a treatment has waived his or her claim to continued treatment. Robbing Peter to pay Paul is different from paying Paul instead of Peter.

\section{Acknowledgements}

Dr Sugarman's work was supported by National Research Service Award 2T32HLO7180-NHLBI. The authors are grateful to Tom L Beauchamp, $\mathrm{PhD}$, Edmund D Pellegrino, MD, and S Carol Taylor, RN, MSN for their critical reviews of earlier drafts of this paper.

Daniel P Sulmasy, OFM, MD, is a Research Scholar at the Center for Clinical Bioethics and Assistant Professor at the Division of General Internal Medicine, Georgetown University Medical Center, Washington, $D C$, USA. Feremy Sugarman, $M D, M A, M P H$, is currently Assistant Professor at the Division of General Internal Medicine, Duke University Medical Center, Durham, North Carolina, USA.

\section{References and notes}

(1) Brock D W. Death and dying. In: Veatch R M, ed. Medical ethics. Boston: Jones and Bartlett, 1989: 329-356.

(2) Veatch R M. Death, dying, and the biological revolution. New Haven, Connecticut: Yale University Press, 1989: 75-76.

(3) Beauchamp T L, Childress J F. Principles of biomedical ethics [3rd ed]. New York: Oxford University Press, 1989: 147-150.

(4) For some pioneering work on these related distinctions, see Glover J. Causing death and saving lives. Middlesex: Penguin Books, 1977: 92-112; Harris J. Violence and responsibility. London: Routledge and Kegan Paul, 1985: 48-65.

(5) In almost all instances, Orthodox Judaism holds that patients must receive all available, effective therapies. On the Orthodox view, questions of withholding and withdrawing medical therapy only become relevant when the patient is in the moribund state termed gesisah. Even here, however, the distinction between withholding and withdrawing medical treatments 
remains morally relevant. See: Bleich J D. The Quinlan case: a Jewish perspective. In: Rosner F, Bleich J D, eds. Fewish bioethics. New York: Sanhedrin Press, 1979: 266-276, especially note 2: 275-276. In contrast to the Orthodox position, conservative Jewish teachings vary on this issue, believing that while withholding and withdrawing medical therapies are morally different, it may be justifiable to withdraw life-sustaining medical therapies in certain instances. See: Dorf E N. A Jewish approach to end-stage medical care. Conservative fudaism 1991; 43: 3-51, especially pages 32-33.

(6) Nozick R. Anarchy, state, and Utopia. New York: Basic Books, 1975: 150-155.

(7) Rawls's difference principle states that an increment in resources for the well-off is only just if it also results in an increase in resources for the least well-off. Under the zero-sum conditions of this case, a gain for one side entails a loss for the other side. Therefore Rawls's difference principle is not applicable to our case. See: Rawls J. A theory of justice. Cambridge, Massachusetts: The Belknap Press of Harvard University Press, 1971: 75-83.

(8) Styron W. Sophie's choice. New York: Random House, 1979.

(9) Ashley B M, O'Rourke K D. Healthcare ethics: a theological analysis [3d ed]. St Louis, Missouri: The Catholic Healthcare Association of the United States, 1989: 384.

(10) The President's Commission. Decisions to forego lifesustaining treatments. Washington, DC: US Government Printing Office, 1983: 73-77.

\section{Continued from page 204}

response is that actual possession does not of itself determine who ought to possess.

Drs Sulmasy and Sugarman have pointed to a real dilemma in practical medical ethics. Their theoretical resolution of that dilemma, despite ingenious thought experimentation, will not, alas, convince all their readers.

\section{References}

(1) Sulmasy D, Sugarman J. Are withdrawing and withholding therapy always morally equivalent? foumal of medical ethics $1994 ; 20$ : 218-222.

(2) Harris J. Are withholding and withdrawing therapy always morally equivalent? A reply to Sulmasy an Sugarman. Fournal of medical ethics 1994; 20: 223-224

\section{Continued from page 206}

(2) Re W. Weekly law reports 1992; 3: 758-782

(3) $\mathrm{Re} \mathrm{R}$. Weekly law reports 1991; 3: 592-608.

(4) Dyer C. Judges give anorexic right to court say. The Guardian 1993 Oct 26.

(5) Re C. Reported in The Independent 1993 Oct 15.

(6) C (a minor) v Director of Public Prosecutions. Reported in The Guardian 1994 Mar 30.

(7) The Children Act 1989. London: HMSO, 1989.

(8) Gillick $v$ West Norfolk and Wisbech Area Health Authority. 1986; 1 Appeal cases: 112-207.
(9) Hodgson D [letter to the editor]. The Guardian 1994 Apr 1.

(10) Dickenson D, Jones D P H. True wishes: philosophical and clinical approaches to the developing case law on consent in children. Philosophy, psychiatry and psychology 1995; 1, 4.

(11) When a patient says no. Lancet 1992; 340: 345.

(12) Eekelaar J. The interests of the child and the child's wishes. In: Alston P, ed. The best interests of the child. Oxford: Oxford University Press, 1994. 